\title{
DETERMINASI IKLIM KOMUNIKASI, KOMPETENSI, DAN DISIPLINKERJA TERHADAP KINERJA PEGAWAI KANTOR DISTRIK NAVIGASI KELAS I TANJUNGPINANG, MELALUI KEPUASAN KERJASEBAGAI INTERVENING
}

\author{
YURITANTO \\ Sekolah Tinggi Ilmu Ekonomi Pembangunan Tanjungpinang \\ yuri.tanto09@gmail.com
}

\begin{abstract}
Research this is a research descriptive quantitative about climate communication, competence, discipline to the performance employee through satisfaction work as a variable intervening. Research this for obtain data and information about climate communication, competence, discipline work and satisfaction employee used as ingredients analysis for knowing the effect to the performance District Office staff Navigation Class I Tanjungpinang, chosen as target research or object research. With framework work this, survey data collection is carried out with make use of questionnaire stage attitude that has been done adapted for topics research this total respondent on research this as many as 142 people. For could characterize attitude, structure model with tool measuring help SmartPLS 3.2.8 for made into as framework work researc.

Results research to show that has been happen circuited an significant between variable Climate communication, competence, and Discipline to Performance employee as big as 40.3 $\%$, and the rest as big as $59.7 \%$ explained by extract others outside of the research in research this. Majority respondent at the location research has been have insight in respond to research this which is based on influence and benefits (impact) for employee that is. Data results research to show has been meet Composite assumption Reliability with value percentage spread as big as $80.6 \%$ for climate communication, $81 \%$ for competence , $79.6 \%$ discipline employee and $85.9 \%$ performance employee and $81 \%$ for satisfaction work employee. Showing that the indicator on each constructor have consistency reability high.
\end{abstract}

Keywords: Climate Communication, Competence, Discipline, Performance Employee, and Satisfaction Work. 


\section{PENDAHULUAN}

Distrik Navigasi kelas I Tanjungpinang adalah salah satu Unit Pelaksana Teknis di lingkungan Direktorat Jenderal Perhubungan Laut, sebagai suatu organisasi, maka Distrik Navigasi Kelas I Tanjungpinang merupakan suatu kesatuan sosial yang dikoordinasikan secara sadar, dengan sebuah batasan yang relatif dapat diidentifikasi, bekerja secara terus menerus untuk mencapai tujuan.

Kondisi kinerja pegawai Kantor Distrik Navigasi Kelas I Tanjungpinang menunjukkan adanya kinerja yang rendah seperti terlambat datang, pemanfaatan jam kerja yang tidak efektif, rasa kepercayaan sesame rekan kerja yang rendah, penyelesaian tugas tidak tepat waktu dan pulang kerja mendahului jam kerja. Padahal di sisi lain, semakin disiplin seorang pegawai, semakin tinggi prestasi kerja yang dapat dicapai. Tanpa disiplin kerja yang baik, sulit bagi organisasi mencapai hasil yang optimal. Disiplin yang baik mencerminkan besarnya rasa tanggungjawab seorang terhadap tugas-tugas yang diberikan kepadanya (Hasibuan, 2014).

Berdasarkan prapenelitian yang dilakukan penulis pada kantor Distrik Navigasi kelas I Tanjungpinang, memiliki masalah yang berhubungan dengan iklim komunikasi yaitu komunikasi yang kurang dapat diserap oleh seluruh sumber daya yang dimiliki antara lain adanya kebijakan pimpinan yang tidak dilaksanakan, kurangnya komunikasi yang dibangun oleh atasan kepada bawahan, banyaknya kebijakan yang kurang tepat sasaran.

Di sisi lain terlihat beberapa permasalahan yang timbul pada kantor Distrik Navigasi kelas I Tanjungpinang diantaranya adalah disiplin pegawai yang kurang baik dan sangat merugikan organisasi dalam mencapai tujuannya, dimana tidak sedikit pegawai yang memiliki kinerja yang buruk, ini dapat dilihat dengan adanya pegawai yang terlambat masuk kantor, banyak juga diantara mereka yang tidak memanfaatkan waktu kerja untuk bekerja. Pada jam-jam kerja pegawai tidak sedikit yang tampak tidak bekerja, akan tetapi mereka menghabiskan waktunya untuk mengobrol, di kantin, dan hal lain yang tidak sesuai dengan harapan.

Berdasarkan latar belakang di atas, maka ditetapkan perumusan masalah penelitian adalah:

1. Apakah Iklim Komunikasi mendeterminasi terhadap Kepuasan kerja pegawai Kantor Distrik Navigasi kelas I Tanjungpinang?.

2. Apakah Kompetensi Pegawai mendeterminasi terhadap Kepuasan kerja pegawai Kantor Distrik Navigasi kelas I Tanjungpinang?.

3. Apakah Disiplin Kerja mendeterminasi terhadap Kepuasan kerja pegawai Kantor Distrik Navigasi kelas I Tanjungpinang?.

4. Apakah Iklim Komunikasi mendeterminasi terhadap Kinerja pegawai Kantor Distrik Navigasi kelas I Tanjungpinang?. 
5. Apakah Kompetensi Pegawai mendeterminasi terhadap Kinerja pegawai Kantor Distrik Navigasi kelas I Tanjungpinang?.

6. Apakah Disiplin Kerja mendeterminasi terhadap Kinerja pegawai Kantor Distrik Navigasi kelas I Tanjungpinang?.

7. Apakah Kepuasan kerja mendeterminasi terhadap Kinerja pegawai Kantor Distrik Navigasi kelas I Tanjungpinang?.

Sebagai mana yang telah ditetapkan pula dalam perumusan masalah, maka tujuan penelitian ini, yaitu : "untuk mengetahui determinasi Iklim Komunikasi langsung terhadap Kepuasan kerja, determinasi Kompetensi langsung terhadap Kepuasan kerja, determinasi Disiplin Kerja langsung terhadap Kepuasan kerja, determinasi Iklim Komunikasi langsung terhadap Kinerja pegawai, determinasi Kompetensi langsung terhadap Kinerja pegawai, determinasi Disiplin Kerja langsung terhadap Kinerja pegawai, determinasi Iklim Komunikasi langsung terhadap Kinerja pegawai, melalui Kepuasan Kerja, determinasi Kompetensi langsung terhadap Kinerja pegawai, melalui Kepuasan Kerja, determinasi Disiplin Kerja langsung terhadap Kinerja pegawai, melalui KepuasanKerja, determinasi Kepuasan kerja langsung terhadap Kinerja pegawai

\section{METODE PENELITIAN}

Adapun penelitian ini akan dilaksanakan pada Januari 2019 s.d Juni 2019 pada Distrik Navigasi kelas I Tanjungpinang. Dalam penelitian ini peneliti menggunakan metode penelitian kuantitatif. Menurut Rumengan (2012:185), populasi adalah sekelompok elemen yang lengkap, yang biasanya berupa objek, orang, transaksi, atau kejadian dimana kita tertarik untuk mempelajarinya atau menjedi objek penelitian. Sedangkan menurut Nasution (2008:86), tiap penelitian memerlukan jumlah objek yang akan diselidiki, secara idealnya objek yang diselidiki secara keseluruhan disebut populasi, apabila populasi terlampau besar maka akan diambil sempel yang representative, yang mewakili keseluruhan populasi.Anggota populasi $(\mathrm{N})$ dalam penelitian ini adalah seluruh pegawai Distrik Navigasi kelas I Tanjungpinang, dimana berdasarkan data kepersonaliaan yang ada, komposisi dan jumlah/populasi pegawai yang ada berjumlah 219 orang.

Menurut Rumengan (2013:57) sempel adalah bagian dari populasi atau wakil populasi yang diteliti dan diambil sebagai sumber data dan dapat mewakili seluruh populasi atau sempel adalah bagian dari jumlah dan karakteristik yang dimiliki oleh populasi.Teknik untuk mendapatkan sempel disebut sebagai teknik sampling. Pengertian dari sampel adalah bagian dari jumlah dan karakteristik yang dimiliki oleh populasi tersebut Sugiyono (2010:8). Bila populasi besar, dan 
peneliti tidak mungkin mempelajari semua yang ada pada populasi, misal karena keterbatasan data, tenaga dan waktu, maka peneliti akan mengambil sampel dari populasi itu. Penarikan anggota sampel (teknik sampling) adalah suatu cara untuk menentukan ukuran/anggota sampel penelitian dan ukuran populasi berdasarkan teknik tertentu. Penarikan anggota sampel dengan teknik sampling, hasilnya diharapkan dapat mewakili karakteristik anggota populasi penelitian (representatif).

Untuk menentukan ukuran sampel dari populasi yang diketahui jumlahnya, dapat menggunakan Rumus Slovin. Rumusnya adalah :

$$
\mathbf{n}=\mathbf{N} / \mathbf{1}+\mathrm{Ne} 2
$$

Keterangan :

$\mathrm{n}=$ Ukuran sampel

$\mathrm{N}=$ Ukuran populasi

$\mathrm{e}=$ Kelonggaran ketidaktelitian karena kesalahan pengambilan sampel yang dapat ditolirir. Dalam penelitian ini kelonggaran yang digunakan adalah sebesar 5\% (0,05). Dengan nilai e $=5 \%$ $(0,05)$ maka didapatkan e $2=0,0025$

Maka berdasarkan rumus diatas didapatkan perhitungan jumlah sampel sebagai berikut :

$\mathrm{n}=219 / 1+(219 \times 0,0025)$

$\mathrm{n}=220 / 1+(0,5475)$

$\mathrm{n}=219 / 1,5475$

$\mathrm{n}=141,51857$ dibulatkan menjadi 142

Hasil diatas merupakan pembagian secara proporsional antara jumlah masing-masing golongan dibandingkan jumlah populasi terhadap jumlah sampel. Alat ukur yang digunakan dalam penelitian ini biasanya dinamakan instrument penelitian, dalam penelitian instrument diartikan sebagai alat untuk mengumpulkan data mengenai variabel-variabel penelitian Rumengan (2013:62). Dalam penelitian ini terdapat 5 (lima) variabel yang akan diteliti yaitu, iklim komunikasi (X1), kompetensi pegawai (X2), Disiplin (X3), kepuasan pegawai (Y), kinerja pegawai (Z). Untuk mempermudah atau mengarah dalam menyusun alat ukur data yang diperlukan berdasarkan kerangka konseptual yang telah diurai dalam batasan operasional dan masing-masing variabel.Variabel penelitian adalah suatu atribut atau sifat atau nilai dari orang, obyek atau kegiatan yang mempunyai variasi tertentu yang ditetapkan oleh peneliti untuk dipelajari dan ditarik kesimpulannya (Sugiyono, 2014: 38). 
Menurut Rumengan (2013: 33) Variabel independen (bebas) adalah variabel yang menjelaskan atau mempengaruhi variabel lain. Variabel independen dalam penelitian ini yaitu: Iklim Komunikasi $\left(\mathrm{X}_{1}\right)$, Kompetensi $\left(\mathrm{X}_{2}\right)$ dan Disiplin Kerja $\left(\mathrm{X}_{3}\right)$. Variabel dependen (tergantung) adalah variabel yang dijelaskan atau yang dipengaruhi oleh variabel independen. Variabel dependen dalam penelitian ini yaitu: Kinerja Karyawan (Y1).

Menurut Tuckman (1988) dalam Sugiyono (2014: 39) Variabel intervening adalah variabel yang secara teoritis mempengaruhi hubungan antara variabel independen dengan dependen menjadi hubungan yang tidak langsung dan tidak dapat diamati dan diukur.Variabel ini merupakan variabel penyela/antara yang terletak diantara variabel independen dan dependen, sehingga variabel independen tidak langsung mempengaruhi berubahnya atau timbulnya variabel dependen. Variabel intervening dalam penelitian ini yaitu: Kepuasan Kerja (Y).

Kalibrasi adalah perbandingan antara pengukuran (standar) yang diketahui dan pengukuran dengan menggunakan instrument.Biasanya, standar keakuratan harus menjadi keakuratan alat ukur yang diuji.Namun, resiko akurasi 3:1 dapat diterima oleh kebanyakan standar organisasi.Seringkali kegiatan yang membentuk hubungan antar nilai yang menunjukan oleh instrument ukur atau system pengukuran, atau nilai yang diwakili oleh bahan ukur, dengan nilainilai yang sudah diketahui yang berkaitan dari sasaran yang diukur dalam kondisi tertentu. (ISO/IEC 17025 \& VIM). Kalibrasi alat ukur memiliki dua tujuan yaitu untuk memeriksa keakuratan instrument dan menentukan ketertelusuran pengukuran.Dalam prakteknya, kalibrasi juga mencakup perbaikan perangkat jika berada di luar kalibrasi.Sebuah laporan diberikan oleh ahli kalibrasi.

Uji rintis (Pilot study) adalah studi pendahuluan sekala kecil yang dilakukan dalam rangka untuk mengevaluasi kelayakan, waktu, biaya, efek samping, dan ukuran efek (variabelitas statistik) dalam upaya untuk memprediksi ukuran sempel yang dapat dan memperbaiki penelitian desain sebelum kinerja dari proyek penelitian skala penuh.Dari hasil pengolahan data dengan SmartPLS yang ditunjukkan bahwa keseluruhan indikator pada masing-masing variabel dalam penelitian ini memiliki nilai loading factor $\leq 0,70$ untuk dilakukan eliminasi terhadap indikator keseluruhnya, yang mana gunanya untuk menghasilkan data yang memiliki validitas dan rebilitas yang baik.

Pengujian validitas dilakukan dengan responden sebanyak 142 responden. Dalam pengujian ini koefisien korelasi kritis diperoleh dari tabel distribusi $r$ dengan menggunakan taraf signifikan 
sebesar $5 \%$ maka $r$-tabel $=0.2140$. Uji signifikansi dilakukan dengan membandingkan nilai $r$ hitung dengan nilai r-tabel.Jika r-hitung lebih besar dari nilai r-tabel, maka pernyataan tersebut dikatakan valid. Dalam penelitian ini dibantu dengan menggunakan software SmartPLS 3.2.8, apabila r-hitung lebih besar daripada $\mathrm{r}$-tabel $=0.2140$ atau lebih, maka analisis pada semua Variabel yang dibahas dalam penulisan Tesis ini dinyatakan valid dan bisa dipakai untuk analisis selanjutnya.

Pengujian ini dilakukan dengan cara one shotatau pengukuran sekali saja. SoftwareSmartPLS

Pada penelitian ini peneliti mengumpulkan data dengan menggunakan kuesioner.Kuesioner adalah lembaran pertanyaan yang berdasarkan indikator variable, kuesioner pula dibagi menjadi dua bentuk yaitu kuesioner dengan pertanyaan terbuka atau dengan pertanyaan tertutup, atau dengan kombinasi keduannya, Romengan (2013:68). Pengumpulan data dalam penelitian ini dalam bentuk koesioner dengan pertanyaan tertutup yakni unit analisis dibatasi sehingga memudahkan dalam perhitungan-perhitungan data yang akan diolah nantinya. Sugiono menyatakan (2009:86) jawaban setiap instrument yang menggunakan skala Likert mempunyai grade dari sangat positif sampai sangat negatif, dapat berupa kata-kata dengan diberi skor. Skala pengukuran yang digunakan dalam penelitian ini untuk mengetahui nilai masing-masing variable eksogen dan variable endogen.Instrumen skala pengukuran yang digunakan dalam penelitian ini adalah skala Likert.Skala Likert adalah jenis skala yang digunakan untuk mengukur sikap, pendapat, dan persepsi seseorang atau kelompok orang tentang kejadian atau gejala social yang sedang berlangsung, Sugiyono (2009:134)

Penelitian ini menggunakan metode analisis data dengan menggunakan software Smart PLS versi 3.2.8 yang dijalankan dengan media komputer. PLS (Partial Least Square) adalah teknik analisis persamaan struktural (SEM) berbasis varian yang secara simultan dapat melakukan pengujian model 33 pengukuran sekaligus pengujian model struktural. Model pengukuran digunakan untuk uji validitas dan reabilitas, sedangkan model struktural digunakan untuk uji kausalitas (pengujian hipotesis dengan model prediksi). Partial Least Squares (PLS) adalah teknik statistika multivarian yang melakukan perbandingan antara variabel dependen berganda dan variabel independen berganda.

\section{HASIL DAN PEMBAHASAN}


Hasil analisis karakteristik responden berdasarkan jenis kelamin dapat ditunjukkan pada Gambar 4.1 :

\section{Gambar 4.1}

\section{Hasil Model Penelitian Algoratma}

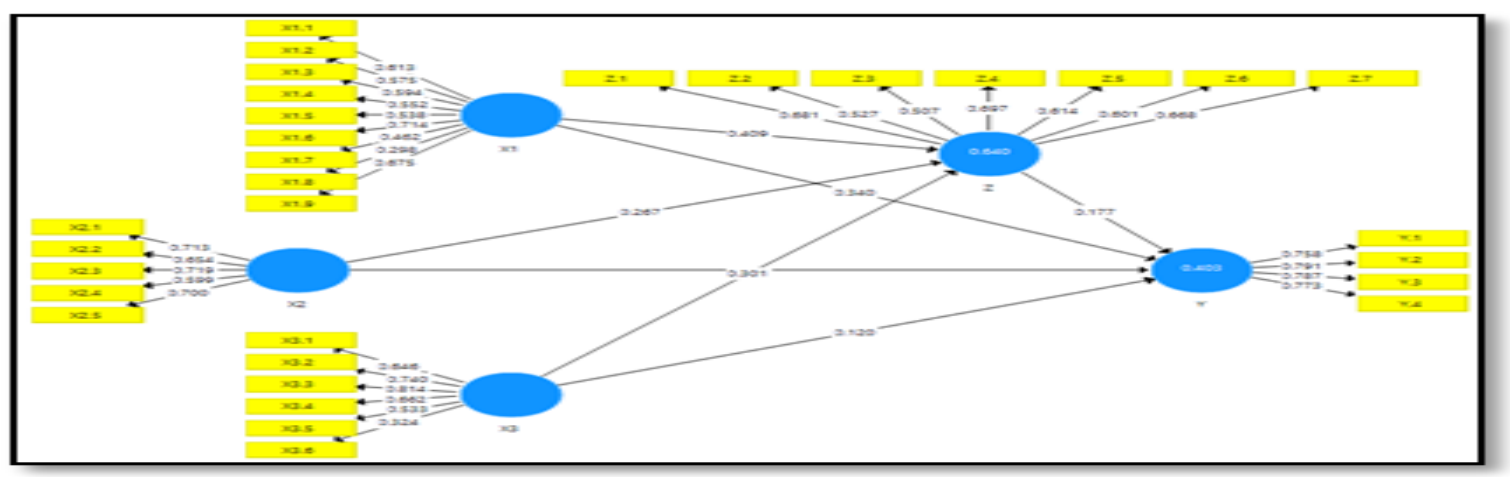

Sumber : Data Primer Diolah, 2019

Model penelitian ini akan dianalisis menggunakan metode Partial Least Square (PLS) dan dibantu dengan software SmartPLS 3.2.8. PLS merupakan salah satu metode alternatif Structural Equation Modeling (SEM) yang dapat dilakukan untuk mengatasi permasalahan pada hubungan diantara variabel yang sangat kompleks tetapi ukuran sampel data kecil (30-100 sampel) dan memiliki asumsi non parametrik, artinya bahwa data tidak mengacu pada salah satu distibusi tertentu (Yamin dan Kurniawan, 2009).

Outer model selain diukur dengan menilai convergent validity dan discriminant validity juga dapat dilakukan dengan melihat reliabilitas konstrak atau variabel laten yang diukur dengan nilai composite reliability. Konstruk dinyatakan reliabel jika composite reliability mempunyai nilai $>0.7$, maka konstrak dinyatakan reliabel.

Convergent Validity dilakukan dengan melihat item reliability (indikator validitas) yang ditunjukkan oleh nilai loading factor.Loading factor adalah angka yang menunjukkan korelasi antara skor suatu item pertanyaan dengan skor indicator konstrak indikator yang mengukur konstrak tersebut. Nilai loading factor lebih besar 0,7 dikatakan valid. Namun, menurut Hair et al. (1998) untuk pemeriksaan awal dari matriks loading factor adalah kurang lebih > 0,3 dipertimbangkan telah memenuhi level minimal, dan untuk loading factor kurang lebih $>0,4$ dianggap lebih baik, dan untuk loading factor lebih besar $>0,5$ secara umum dianggap signifikan. Dalam penelitian ini batas loading factor yang digunakan sebesar 0,7 .

Dari hasil pengolahan data dengan SmartPLS yang ditunjukkanbahwa keseluruhan indikator pada masing-masing variabel dalam penelitian ini memiliki nilai loading factor yang lebih besar dari 0,70 
dan dikatakan valid. Hal ini menunjukkan tingkat validitas yang baik, hal ini juga setelah dilakukannya eliminasi terhadap indikator yang memiliki nilai loading factor yang kecil/rendah, dengan demikian indikator variabel yang memiliki nilai loading factor lebih besar dari 0,70 memiliki tingkat validitas yang tinggi, sehingga memenuhi convergent validity. Sedangkan indikator variabel yang memiliki nilai loading lebih kecil dari 0,70 memiliki tingkat validitas yang rendah sehingga indikator variabel tersebut perlu dieliminasi atau dihapus dari model.

\section{Tabel 4.1. Nilai AVE danAkarKuadrat AVE}

\begin{tabular}{|l|c|c|}
\hline & $\begin{array}{c}\text { AverageVariance Extracted } \\
\text { (AVE) }\end{array}$ & Akar Kuadrat AVE \\
\hline Iklimkomunikasi & 0.324 & 0,570 \\
\hline Kompetensi & 0.461 & 0,679 \\
\hline Disiplin & 0.409 & 0,640 \\
\hline Kinerja pegawai & 0.604 & 0,777 \\
\hline Kepuasan kerja & 0.382 & 0,618 \\
\hline
\end{tabular}

Sumber : Data Primer Diolah, 2019

Discriminant Validity dilakukan dengan cara melihat nilai cross loading pengukuran konstrak. Nilai cross loading menunjukkan besarnya korelasi antara setiap konstrak dengan indikatornya dan indikator dari konstrak blok lainnya. Suatu model pengukuran memiliki discriminant validity yang baik apabila korelasi antara konstrak dengan indikatornya lebih tinggi daripada korelasi dengan indikator dari konstrak blok lainnya. Setelah dilakukan pengolahan data dengan menggunakan SmartPLS 3.0.

Evaluasi selanjutnya, yaitu dengan membandingkan nilai akar AVE dengan korelasi antar konstrak. Hasil yang direkomendasikan adalah nilai akar AVE harus lebih tinggi dari korelasi antar konstrak (Yamin dan Kurniawan, 2011). Model memiliki discriminant validity yang lebih baik apabila akar kuadrat AVE untuk masing-masing konstrak lebih besar dari korelasi antara dua konstrak di dalam model. Nilai AVE yang baik disyaratkan memiliki nilai lebih besar dari 0,50. Dalam penelitian ini, nilai AVE dan akar kuadrat AVE untuk masing-masing konstrak dapat ditunjukkan pada Tabel 4.1.

Berdasarkan Tabel 4.1 semua konstrak menunjukkan nilai AVE yang lebih kecil dari 0,50 yaitu dengan nilai terkecil 0,342 untuk variabel Iklim komunikasi dan terbesar 0,604 untuk variabel Kinerja pegawai. Nilai tersebut tidak memenuhi persyaratan sesuai dengan batas nilai minimum AVE 
yang ditentukan yaitu 0,50. Setelah diketahui nilai akar kuadrat dari AVE untuk masing-masing konstrak, tahap selanjutnya adalah membandingkan akar kuadrat AVE dengan korelasi antar konstrak dalam model. Pada penelitian ini hasil dari korelasi antar konstrak dengan nilai akar kuadrat AVE dapat ditunjukkan pada Tabel

4.2 berikut:

Tabel 4.2

Nilai korelasi antar konstrak dengan nilai akar kuadrat AVE

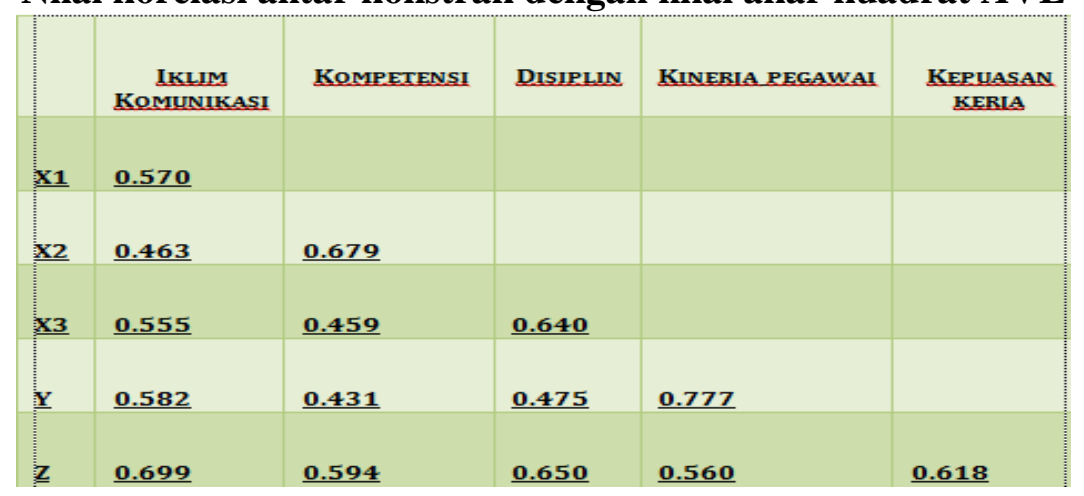

Sumber : Data Primer Diolah, 2019

Setelah pengujian outer model yang telah memenuhi, berikutnya dilakukan pengujian inner model (model structural). Inner model dapat dievaluasi dengan melihat r-square (reliabilitas indikator) untuk konstrak dependen dan nilait-statistik dari pengujian koefisien jalur (path coefficient). Semakin tinggi nilair-square berarti semakin baik model prediksi dari model penelitian yang diajukan. Nilai path coefficients menunjukkan tingkat signifikansi dalam pengujian hipotesis.

Analisis Variant (R2) atau Uji Determinasi yaitu untuk mengetahui besar pengaruh variabel endogen terhadap variabel eksogen tersebut, nilai dari koefisien determinasi dapat ditunjukkan pada Tabel 4.3 berikut :

Tabel 4.3

Nilai R-square

\begin{tabular}{|l|l|l|}
\hline & R Square & \multicolumn{1}{|l|}{$\begin{array}{l}\text { R Square } \\
\text { Adjusted }\end{array}$} \\
\hline $\begin{array}{l}\text { Kinerja Pegawai } \\
\text { Kepuasan Kerja }\end{array}$ & 0,403 & 0,385 \\
\hline
\end{tabular}

Sumber : Data Primer Diolah, 2019

Berdasarkan nilai r-square pada Tabel 4.3 menunjukkan bahwa telah terjadi hubungna yang signifikan antara variabel Iklim komunikasi, Kompetensi, dan Disiplin terhadap Kinerja pegawai sebesar 40,3\%, dan sisanya sebesar 59,7\% diterangkan oleh konstrak lainnya diluar yang diteliti 
dalam penelitian ini. Sedangkan variabel Iklim komunikasi, Kompetensi, dan Disiplin mampu menjelaskan hubungan yang signifikan terhadap Kepuasan kerja sebesar 64\%, dan sisanya sebesar $36 \%$ diterangkan oleh konstrak lainnya diluar yang diteliti dalam penelitian ini.

\section{Pengujian Hipotesis}

Pengujian Hipotesis dilakukan berdasarkan hasil pengujian Inner Model (model struktural) yang meliputi output r-square, koefisien parameter dan t-statistik. Untuk melihat apakah suatu hipotesis itu dapat diterima atau ditolak diantaranya dengan memperhatikan nilai signifikansi antar konstrak, tstatistik, dan p-values. Pengujian hipotesis penelitian ini dilakukan dengan bantuan software SmartPLS (Partial Least Square) 3.2.8 Nilai-nilai tersebut dapat dilihat dari hasil bootstrapping. Rules of thumb yang digunakan pada penelitian ini adalah t-statistik $>1,96$ dengan tingkat signifikansi p-value 0,05 (5\%) dan koefisien beta bernilai positif.

Gambar 4. 2 Hasil Model Penelitian Bootstrapping

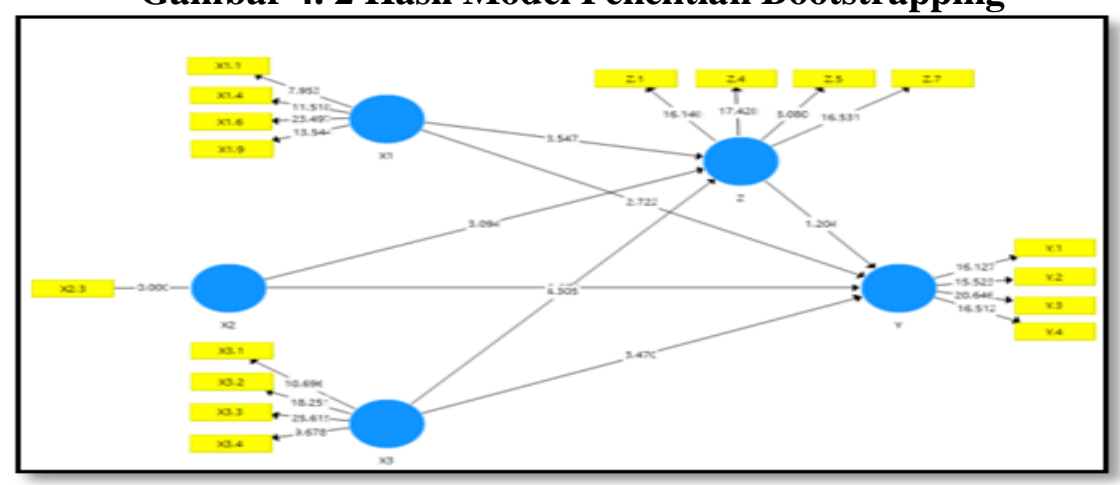

Sumber : Data Primer Diolah, 2019

Gambar 4.4

Hasil Path Coefficients

\begin{tabular}{|c|c|c|c|c|c|}
\hline 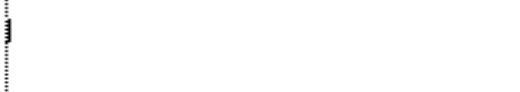 & $\begin{array}{c}\text { Original } \\
\text { Sample } \\
\text { (O) }\end{array}$ & $\begin{array}{c}\text { Sample } \\
\text { Mean } \\
\text { (M) }\end{array}$ & $\begin{array}{l}\text { Standard } \\
\text { Deviation } \\
\text { (STDEV) }\end{array}$ & $\begin{array}{l}\text { T Statistics } \\
\text { C|O/STDEVD }\end{array}$ & P Values \\
\hline Iklim Komunikasi -> Kinexja pegawai & 0.340 & 0.360 & 0.103 & 3.303 & 0.001 \\
\hline Iklim Komunikasi $\rightarrow$ Kepuasan kexja & 0.409 & 0.411 & 0.073 & 5.624 & 0.000 \\
\hline Kompetensi $\rightarrow$ Kinexja pegaxai & 0.114 & 0.122 & 0.091 & 1.257 & 0.209 \\
\hline Kompetensi -> Kepuasan kerja & 0.267 & 0.268 & 0.068 & 3.901 & 0.000 \\
\hline Disiplin $\rightarrow$ Kinexia pegawai & 0.120 & 0.120 & 0.094 & 1.275 & 0.202 \\
\hline Disiplin -> Kepuasan kexja & 0.301 & 0.302 & 0.079 & 3.809 & 0.000 \\
\hline Kepuasan kerja $\rightarrow$ Kinexia pegawai & 0.177 & 0.159 & 0.127 & 1.394 & 0.163 \\
\hline
\end{tabular}


Sumber : Data Primer Diolah, 2019

\section{Indirect Effect}

Indirect Effect berguna untuk menguji hipotesis pengaruh tidak langsung suatu variabel yang mempengaruhi (Eksogen) terhadap variabel yang dipengaruhi (Endogen) yang dantarai oleh suatu variabel intervening . secara sederhana hasil tidak langsung indirect effect adalah dari X terhadap Y melalui Z, atau dapat digambarkan sebagai berikut:

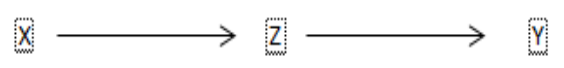

\section{Gambar 4.5}

Total Indirect Effect

\begin{tabular}{|c|c|c|c|c|c|}
\hline & $\begin{array}{l}\text { Original } \\
\text { Sample } \\
\text { (O) }\end{array}$ & $\begin{array}{c}\text { Sample } \\
\text { Meam (MD) }\end{array}$ & $\begin{array}{l}\text { Standard } \\
\text { Deviation } \\
\text { (STDEV) }\end{array}$ & $\begin{array}{c}\text { T } \\
\text { Statistics } \\
(\mid O / S T D E V D\end{array}$ & $\frac{\mathbf{P}}{V \text { alues }}$ \\
\hline $\mathbf{X I} \rightarrow \mathbf{Z} \rightarrow \mathbf{Y}$ & 0.072 & O.065 & 0.054 & 1.334 & 0.182 \\
\hline $\mathbf{X Z} \rightarrow \mathbf{Z} \rightarrow \mathbf{Y}$ & $\mathrm{O} .047$ & 0.042 & 0.036 & 1.318 & 0.187 \\
\hline$X 3 \rightarrow Z \rightarrow Y$ & O.053 & O.049 & $\mathrm{O} .042$ & 1.274 & 0.203 \\
\hline
\end{tabular}

Sumber : Data Primer Diolah, 2019

\section{Total Effect}

Pengaruh langsung, tidak langsung dan total atau disebut sebagai direct, indirect, and total effect, dapat digunakan untuk mengetahui dan melihat pengaruh variabel-variabel satu dengan lainnya secara langsung, tidak langsung dan total pengaruh.

Tabel 4.9

Total Effect

\begin{tabular}{|l|c|c|c|c|c|}
\hline & $\begin{array}{c}\text { Original } \\
\text { Sample (O) }\end{array}$ & $\begin{array}{c}\text { Sample } \\
\text { Mean (M) }\end{array}$ & $\begin{array}{c}\text { Standard } \\
\text { Deviation } \\
\text { (STDEV) }\end{array}$ & $\begin{array}{c}\text { T } \\
\text { Statistics } \\
\text { (S/STDEV] }\end{array}$ & P Values \\
\hline $\mathbf{X 1}>\mathbf{Y}$ & 0.412 & 0.425 & 0.084 & 4.906 & $\mathbf{0 . 0 0 0}$ \\
\hline $\mathbf{X 1}>\mathbf{Z}$ & 0.409 & 0.411 & 0.073 & 5.624 & $\mathbf{0 . 0 0 0}$ \\
\hline $\mathbf{X} \mathbf{2}>\mathbf{Y}$ & 0.161 & 0.164 & 0.083 & 1.931 & $\mathbf{0 . 0 5 4}$ \\
\hline $\mathbf{X} \mathbf{2} \rightarrow \mathbf{Z}$ & 0.267 & 0.268 & 0.068 & 3.901 & $\mathbf{0 . 0 0 0}$ \\
\hline $\mathbf{X} \mathbf{3}>\mathbf{Y}$ & 0.173 & 0.168 & 0.089 & 1.939 & $\mathbf{0 . 0 5 3}$ \\
\hline $\mathbf{X 3}>\mathbf{Z}$ & 0.301 & 0.302 & 0.079 & 3.809 & $\mathbf{0 . 0 0 0}$ \\
\hline $\mathbf{Z}>\mathbf{Y}$ & 0.177 & 0.159 & 0.127 & 1.394 & $\mathbf{0 . 1 6 3}$ \\
\hline
\end{tabular}

Sumber : Data Primer Diolah, 2019

\section{Simpulan}

Berdasarkan obyek penelitian yang terdapat kesenjangan antara teori dengan fakta empiris, dan disusunlah kerangka berpikir berdasarkan teori yang ada, maka disusunlah Devenisi Operasional Variabel. Kuesioner yang direspon oleh Responden para Pegawai di Distrik Navigasi kelas I 
Tanjungpinang dan proses penghitungan data menggunakan software SmartPLS 3.2.8.Maka hasil penelitian ini pada bagian ini akan menjelaskan hasil analisis penelitian. Tujuan dari penelitian ini pula adalah untuk mengetahui faktor paling berpengaruh dalam kinerja pegawai di Kantor Distrik Navigasi Kelas I Tanjungpinang. Mengingat literatur sebelumnya, penelitian ini menggunakan lima variabel sebagai mana telah dijelaskan tiga variabel endogen dan dua variabel eksogen, yaitu iklim komunikasi, kompetensi, dan disiplin untuk mengetahui hubungan antara kepuasan pegawai dan akhirnya, pengaruhnya terhadap kinerja pegawai. Selain itu, efek moderat dari kinerja pegawai telah diperiksa. Sebanyak tujuh hipotesis dikembangkan dan diuji dengan metode Structural Equation Modeling (SEM) dan di bantu dengan software SmartPLS 3.0.

\section{Saran}

Berdasarkan kesimpulan dari hasil penelitian tersebut diatas, sesuai dengan tujuan penelitian ini, maka dapat disarankan kepada Distrik Navigasi Kelas I Tanjungpinang dan untuk kemajuan ranah keilmuan ekonomi manajemen, Maka hasil penelitian ini dapat dijadikan referensi dan acuan bagi pimpinan atau pihak manajemen organisasi Kantor Distrik Navigasi Kelas I Tanjungpinang dengan memperhatikan hal iklim komunikasi, kompetensi, disiplin kerja, kepuasan kerja, dan kinerja pegawai sehingga dapat meningkatkan kinerja pegawai Kantor Distrik Navigasi Kelas I Tanjungpinang melalui kepuasan kerja.

\section{Ucapan Terima Kasih}

Rasa terimakasih penulis berikan kepada Bapak Prof. Dr. Ir. Jemmy R, SE, MM selaku Pembimbing I dan Ibu Dr. Indrayani, SE, MM selaku Pembimbing II yang telah membantu saya menyelesaikan tesis ini. Serta ucapan rasa terimakasih kepada :

1. Bapak Dr. Ir. Chablullah Wibisiono, MM selaku Rektor Universitas Batam;

2. Bapak Prof. Fachrudin, MSM, Ph.D selaku Dekan Fakultas Ekonomi Universitas Batam;

3. Ibu Sri Yanti, SE, M.Si selaku Ketua Program Studi Manajemen Universitas Batam;

4. Bapak Jamin Hasibuan, ST selaku Kepala Kantor Distrik Navigasi kelas I Tanjungpinang;

5. Rekan-rekan pegawai Kantor Distrik Navigasi kelas I Tanjungpinang;

6. Seluruh teman-teman dan sahabat yang dalam hal ini tidak dapat penulis menyebutnya satu persatu. 


\section{Journal Competency of Business 2020 Vol 4. No I}

Akhir kata penulis menyadari bahwa dalam penulisan tesis ini masih jauh dari kesempurnaan. Karena itu, penulis memohon saran dan kritik yang sifatnya membangun demi kesempurnaannya dan semoga bermanfaat bagi kita semua. Amiinya Rabbalalamin 


\section{DAFTAR PUSTAKA}

Emyria Natalia br S, Abdul Hoyyi, Rukun Santoso. 2017. Badan Arsip dan Perpustakaan Daerah Provinsi Jawa Tengah

H. M. Arsyad al-Makki. 2010. Smart Partial Least Square. Universitas Sunan Kalijaga

Raja Abdul Ghafoor Khan, Furqan Ahmed Khan, dan Dr. Muhammad Aslam Khan. (2011). Impact of Training and Development on Organizational Performance.Global JournalsInc.[Online].11(7), 62-68.http://journalofbusiness.org

AA. Anwar Prabu Mangkunegara, (2009). Manajemen Sumber Daya Manusia Perusahaan.Bandung : Rosda.

Devi, V. R. \& Shaik, N. (2012). Training \& Development-A Jump Starter for EmployeePerformance and Organizational Effectiveness. International Journal of Social Scienceand Interdisciplinary Research, Volume 1(7), 202-207.

Elya Nurwullan, Suharno, Netti Tinaprilla. 2015. Balai Besar Penelitian dan Pengkajian Teknologi Pertanian Kota Bogor.

Parulian Hutapea, MBA, DR. Nurianna Thoha, MBA. 2008. Kompetensi Plus Penerbit PT. Gramedia Pustaka Utama Jakarta.

R. Wayne Pace, Don F. Faules. 2018. Komunikasi Organisasi Penerbit PT. Remaja Rosdakarya Bandung.

Hair, J. F., Hult, G. T. M., Ringle, C. M., \& Sarstedt, M. (2017). A Primer on Partial Least Squares Structural Equation Modeling.

Andika Wishnu Setyaji. 2015. Tesis. Universitas Sebelas Maret Surakarta.

http://www.jonathansarwono.info/teori_spss/PLSSEM.pdf.

http://www.konsultanstatistik.com/2010/10/simulasi-smartpls_852.html

https://www.smartpls.com/free-trial 